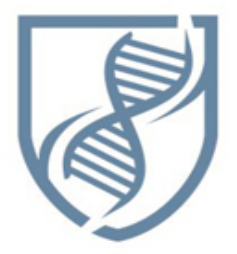

Journal of Bioscience and Applied Research
JBAAR

WWW.JBAAR.ORG

\title{
Effect of L-arginine on methotrexate induced hepatotoxicity in albino rats
}

\author{
Ashour A - S Abdel-Mawla ${ }^{1}$, Safia M Hassan², Ekram N Abd Al-Haleem³ and Safeyah Z El- \\ Hangoor $^{4}$ \\ ${ }^{1,2}$ Histochemistry and Cell Biology Department, Medical Research Institute Alexandria University. \\ ${ }^{3,4}$ Pharmacology and Toxicology Department Faculty of Pharmacy (Girls), Al- Azhar University.
}

(Corresponding author e.mail.dr_safiahassan@yahoo.com)

\begin{abstract}
Methotrexate (MTX) is commonly used in the treatment of many different types of cancer and inflammatory diseases. Its cytotoxic nature also lends a substantial risk of life-threatening side effects. L-arginine is beneficial in the treatment of hepatic injury, hepatic cirrhosis and fatty liver degeneration. The present work aims to study the effect of L-arginine on hepatotoxicity of methotrexate in albino rats. Five groups of albino rats were used. Group I: control. Group II: rats were administered (MTX) in a daily oral dose of $0.45 \mathrm{mg} / \mathrm{kg}$, for 28 days. Group III: rats were administered L-arginine in a daily oral dose of $300 \mathrm{mg} / \mathrm{kg}$, for 28 days. Group IV: rats were received L- arginine 2 hrs before (MTX). Group V: rats were received L-arginine 2 hrs after (MTX). The results revealed different histopathological changes in liver of MTX-treated rats such as focal areas of necrosis and increased numbers of activated Kupffer cells, an apparent increase in the amount of collagen fibers and strong immunoreactive expression of $\alpha$-SMA. Biochemical results revealed a significant increase in the serum levels of ALT, AST, bilirubin and decreasing the level of antioxidant enzymes. L-agrinine minimized the hepatotoxicity of MTX by decreasing the level of ALT, AST and bilirubin, MDA and increasing the antioxidant enzymes. It is concluded that L-arginine protects liver from hepatotoxicity of methotrexate and this due to its antioxidant activity.
\end{abstract}

Key words: Liver, Methotrexate, L-arginine, $\alpha$-SMA, ALT, AST, bilirubin, SOD, GSH and MDA

\section{Introduction}

Liver injury may be acute or chronic and there can be development. It is the precursor for the synthesis of protein, adapted to injurious effects with a transient increase in liver nitric oxide (NO), creatine, agmatine, and polyamines, and function with significant ongoing injury. Many factors interact to lead to injury and there is considerable variation in susceptibility which may be inherited or acquired. In other words, injury may be a direct toxic effect or immunological reaction to either the drug or an active metabolite formed by bioactivation (Brind, 2007). Methotrexate (MTX), a folate antagonist, is commonly used in the treatment of many different types of cancer and inflammatory diseases such as rheumatoid arthritis, psoriatic arthritis, systemic lupus erythematosis and dermatomyositis ( Dalaklioglu et al., 2013). While MTX is generally well-tolerated by patients, its cytotoxic nature also lends a substantial risk of life-threatening side effects the most severe of which are hematopoietic suppression, hepatotoxicity and pulmonary toxicity (Soliman, 2009, Cetin et al., 2011. Kose et al., 2012). The conversion of MTX to its major extracellular metabolite (7hydoxymethotrexate) takes place in the liver, where it is oxidized by a soluble enzymatic system (Chladek et al. , 1997). Inside cells, MTX is stored in a polyglutamated form. Long-term drug administration can cause accumulation of MTX polyglutamates and decreased folate levels (Kamen et al, 1981). The presence of higher levels of polyglutamates causes a longer intracellular presence of the drug, and this has been suggested as a mechanism for MTX hepatotoxicity (Kremer et al, 1986). Moreover, the levels of liver malondialdehyde, as products of lipid peroxidation, were increased after treatment with MTX to levels that are found to be significantly higher than those in the control animals while liver GSH levels were significantly decreased (Jahovic et al., 2003).

L-arginine is an essential amino acid for optimal growth and 
is an intermediate in the detoxification of ammonia for young organisms. Therefore it must be provided in the diet. For adults, L-arginine is a semi-essential or conditionally essential amino acid, especially in such conditions as trauma, burn injury, small- bowel resection, and renal failure (Scibior and Czeczot, 2004). In adults, L-arginine is produced in the kidney from circulating citrulline synthesized by enterocytes in the small intestine (Wouter et al., 2004). Several experimental studies have revealed that the administration of L-arginine can reduce renal ischemia reperfusion injury to skeletal muscle, kidney, liver, heart and brain. Moreover, L-arginine administration improves cardiovascular, pulmonary, immune, digestive functions, protects against the early stages of carcinogenesis and causes protective hemodynamic alterations. However, in situations with a stimulated inducible nitric oxide synthase (iNOS), the administration of large amounts of L-arginine is considered to be hazardous for the patients (Roth, 1998). NO was identified as the biologically active intermediate of the arginine (Hibbs et al.,1988).It is known that many cell types utilize arginine to generate $\mathrm{NO}$, which plays important roles in many diverse processes, including vasodilation, immune responses, neurotransmission and adhesion of platelets and leucocytes (Bredt and Snyder, 1994). Larginine is beneficial in the treatment of hepatic injury, hepatic cirrhosis and fatty liver degeneration (Balch et al., 1997).The present work aims to study the effect of Larginine on hepatotoxicity of methotrexate in albino rats.

\section{Materials and Methods}

This study was consisted of 60 adult male albino rats weighing approximately 100-120 g. obtained from Animal House of Medical Research Institute of Alexandria University. Animals were housed with food and water ad libitum, stander light - dark cycle (12: 12 - h) at optimum temperature $(23 \pm 1 \mathrm{C})$. All animals' procedures were performed according to the principles in the Guide lines of Care and Use of Laboratory Animals, and were approved by the Institutional animal ethics committee.

Rats were divided into 5 groups:

Group I: 10 rats were served as control.

Group II: 10 rats were administered MTX in a daily oral dose of $0.45 \mathrm{mg} / \mathrm{kg}$, for 28 days.

Group III: 10 rats were administered L-arginine in a daily oral dose of $300 \mathrm{mg} / \mathrm{kg}$, for 28 days.

Group IV (Protection group): 15 rats received L- arginine 2 hrs before administration of MTX.

Group V (Curative group): 15 rats received L-arginine 2 hrs after administration of MTX.

\section{Histological study:}

Rats were sacrificed 24 hours after last drug administration. For histological preparations: small pieces of liver were fixed, dehydrated, cleared and mounted. Sections of $5 \mu \mathrm{m}$ were stained with Hematoxylin and Eosin (Bancroft and Stevens, 2002). Collagen was demonstrated in hepatic tissue using Masson's trichrome method (Kierman, 2001).

\section{Immunohistochemical localization of Alpha smooth} muscle actin:

Sections of $4 \mu \mathrm{m}$ thickness were cut and mounted onto coated glass slides. They were incubated with methanol-1\% hydrogen peroxide to destroy endogenous peroxidase, and blocked with nonspecific staining blocking reagent (Sigma Co.). After overnight incubation at $4^{0} \mathrm{C}$ in mouse monoclonal anti- $\alpha$-SMA antibody (diluted 1:100; Sigma) sections were processed according to the standard immunoperoxidase method, using a streptavidin biotin peroxidase complex kit (Sigma Co.). The immunohistochemical reaction was then developed and stained with diaminobenzidine chromogen solution "DAB"(Sigma). Sections were counter stained with hematoxylin, dehydrated, cleared, and mounted with DPX. Negative control was obtained by omitting primary antibody (Skalli et al., 1986).

Image analysis: Imported data were analyzed quantitatively by Leica Q-500 MC Software for collagen and $\alpha$-SMA.

Biochemical analysis:

Sera were collected for measurement of serum ALT and AST (Reitman et al., 1957) and Bilirubin. (Jendrassik and Grof, 1938). Lipid peroxidation marker (malondialdehyde, MDA) and antioxidant enzymes, superoxide dismutase (SOD) and hepatic glutathione (GSH) activity were detected in liver homogenates using the methods of Okawa et al., 1979, Richardson and Murphy,1975, and Marklund and Marklund,1974,respectively.

\section{Statistical analysis:}

Results were expressed as mean \pm standard error and analyzed using Microsoft Excel and Student's " $t$ " test using Origin 41 program at levels of significance $\mathrm{P} \leq 0.05$ and $\leq$ 0.01 (Snedecor and Cochran, 1980).

\section{Results}

\section{3. $i$.Change in liver weight:}

Data in table (1) showed that L-arginine did not induce any significant change in relative liver weight compared to normal control group, On the other hand, relative liver weights of methotrexate-intoxicated rats were significantly increased by $66.5 \%$ compared to normal control group, also in protection group there was no significant increase in the relative liver weight compared to normal control group, while curative group showed a slight increase by $28.28 \%$ compared to normal control.

\section{3. ii. Histological results}

Normal control liver sections showed normal histological features, hepatic lobular architecture is preserved, hepatic cells are arranged in cord separated by widened sinusoid lined by simple flat endothelium with Kupffer cells, hepatic cells show normal nucleus/cytoplasmic ratio, nuclei are small round and densely stained. Majority of hepatocytes have single nuclei and some binucleated cells are also observed (Fig.1). Liver sections of rats that received L-arginine for 28 days showed no pathological changes. 
Table (1): Protective and curative effect of L-arginine on Relative liver weights in Methotrexate-induced hepatotoxicity in rats

\begin{tabular}{|c|c|c|c|c|c|}
\hline Groups & Control & L-arginine & Methotrexate & Protected & curative \\
\hline $\begin{array}{c}\text { Relative liver } \\
\text { weight (\%) }\end{array}$ & $\begin{array}{c}3.586 \\
\pm \\
0.191\end{array}$ & $\begin{array}{c}3.314 \\
\pm \\
0.199\end{array}$ & $\begin{array}{c}5.971 \\
\pm \\
0.114^{\mathrm{a}, \mathrm{b}}\end{array}$ & $\begin{array}{c}3.814 \\
\pm \\
0.22^{c}\end{array}$ & $\begin{array}{c}4.6 \\
\pm \\
0.16^{\text {a,b,c,d }}\end{array}$ \\
\hline
\end{tabular}

- Values are mean \pm SEM of seven animals.

- a, b, c or d: indicates a significant difference from control, L-arginine, Methotrexate, protection or curative groups, respectively at $\mathrm{p}<0.05$ using one way ANOVA followed by Tukey-Kramer test for multiple comparisons.

In MTX group severe pathological changes were observed, wide spread necrosis with acute inflammation and apoptotic changes such as pyknosis, karyorrhexis and karyolysis in liver are present. Lobular disarray as well as dilatation of centrolobular sinusoids was also observed. Vascularitis, represented by congested central vein and perivascular edema and lymphocytes infiltrations was noticed (Figs.2a, b). Pretreatment with L-arginine obviously reduced the hepatic injury. Liver sections of protected group showed mild pathological changes. Congestion of central vein and some apoptosis was noticed. Hepatic lobular architecture was preserved (Fig.3). Larginine post-treatment showed moderate pathological changes. Scattered areas of necrosis among inflammatory infiltrate are still present with dilated sinusoids. Karyolysis and karyorrhexis were noticed (Fig.4).

Masson's trichrome stain was used to detect collagen deposition (stained blue) and to estimate the degree of fibrosis in rat liver sections. Examined liver sections of normal control rats (Fig.5) or L-arginine group (Fig.6) showed minimal deposition of connective tissues as thin rims of collagen around central vein and sinusoids. Liver sections of rats administered MTX revealed increased fibrosis and showed strong thickening of collagen fibers at portal area, central vein and sinusoids (Fig.7). Pretreatment with L-arginine decreased collagen fibrosis, compared with their counterparts in MTX group, to a weak or moderate collagen deposition around central vein and sinusoids (Fig.8). Post- treatment with L-arginine also decreased collagen deposition, compared to MTX group, to moderate collagen deposition around central vein and sinusoids (Fig.9).

By using software (leica Q-500) to assess collagen positivity, the comparison between the different groups showed that collagen positivity was significantly increased in MTX-intoxicated group compared to normal control group and that post and pre-treatment with L-arginine significantly decreased collagen positivity compared to MTX-intoxicated group.

\section{3. iii. Immunohistochemical results}

Immunohistochemical assessment of $\alpha$-SMA expression in rat livers was observed as brown positive staining in smooth muscle cells present in vascular walls of central vein as well as in perisinusoidal cells. Examined liver sections of normal control rats and l-arginine group showed mild positive immunostaining of $\alpha$-SMA around central vein and in sinusoidal lining (Figs.10\&11). Liver section of rat administered MTX revealed strong homogenous positive staining $\alpha$-SMA in sinusoids. Marked proliferation of smooth muscle cells around central vein with strong positivity of $\alpha$-SMA was noted (Figs.12\&13). Pretreatment with L-arginine reduced $\alpha$-SMA expression in hepatic tissue (Fig.14). Post- treatment with L-arginine still showed expression of $\alpha$-SMA in vascular walls of central vein and in perisinusoidal cells (Fig.15).

By using software (leica Q-500) to assess $\alpha$-SMA positivity in different groups showed that $\alpha$-SMA positivity was significantly increased in MTX-intoxicated group compared to normal control group and that post and pretreatment with L-arginine significantly decreased $\alpha$-SMA positivity compared to MTX-intoxicated group.

\section{3.iv. Biochemical results}

a. Change in AST, ALT and bilirubin:

L-arginine did not induce any significant results in AST serum level compared to normal control group, while MTX induced significant increase in AST serum level mounted to $110.6 \%$ compared to normal control group, this percentage is significantly diminished by administration of L-arginine 2 hrs before and after methotrexate to $14 \%$ and $40 \%$ respectively compared to normal control group (Fig.16). L-arginine did not induce any significant results in ALT serum level compared to normal control group, while MTX induced significant increase in ALT serum level mounted to 142. 5\%. 

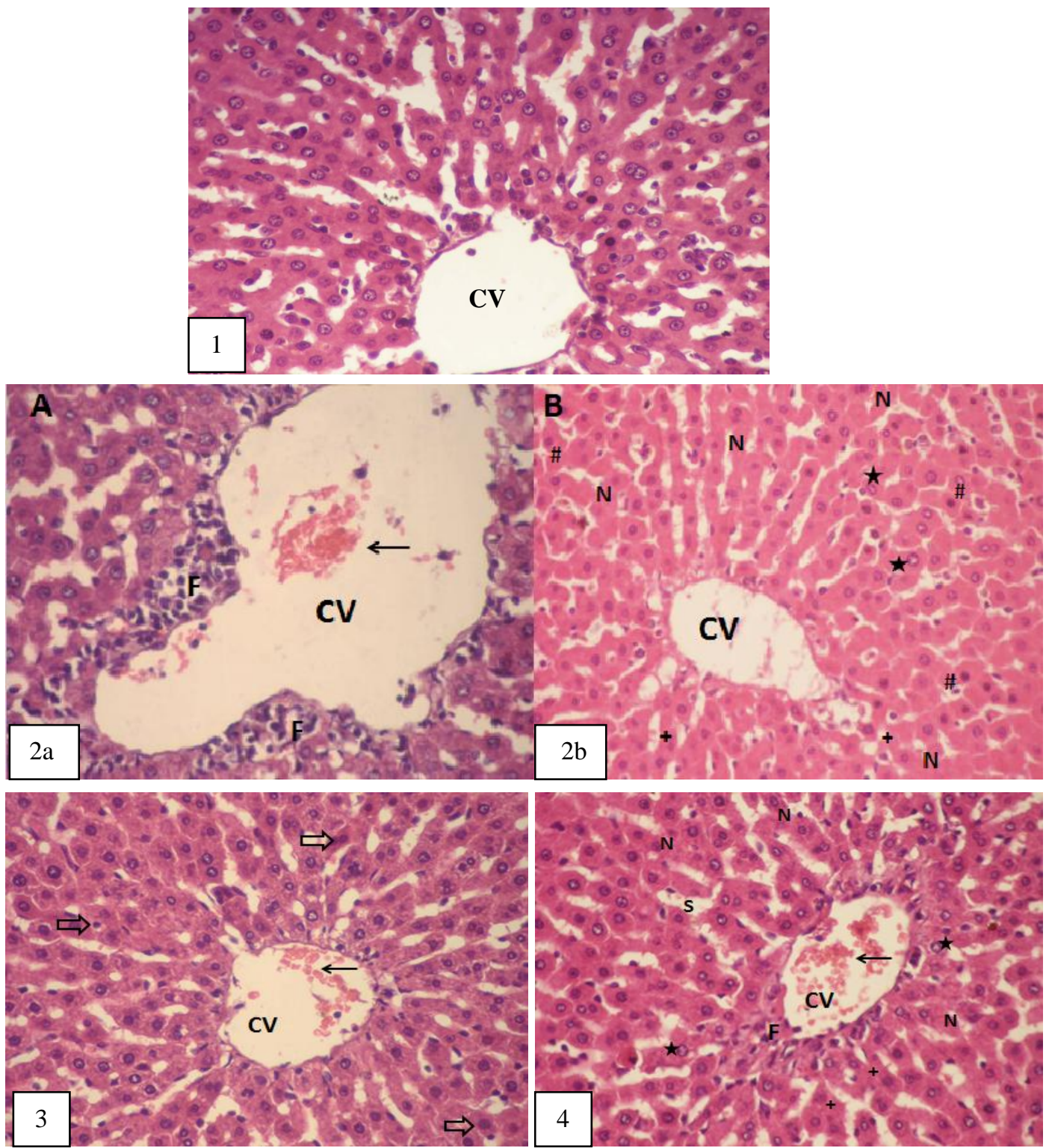

Fig.1. photomicrograph of liver section of a control rat showing normal hepatic cells, central vein (CV) and slight sinusoidal dilatation (S).(H\&E X 400).

Fig.2. photomicrograph of rat liver section after receiving MTX for 28 days showing severe pathological changes (a)congested central vein $(\leftarrow)$, perivascular inflammation $(\mathbf{F}) .(\mathbf{b})$ - necrosis(N) and apoptotic changes: pyknosis(\#), karyorrhexis( *) and karyolysis(+) (H\&E X 400).

Fig.3. photomicrograph of rat liver section after treatment with L-arginine 2 hrs before MTX for 28 days showing reduction in hepatic injury with mild congestion of central vein $(\leftarrow)$ and some apoptosis $(\Rightarrow)$.(H\&E X 400).

Fig.4. photomicrograph of rat liver section after treatment with L-arginine 2 hrs after MTX for 28 days showing moderate pathological changes; congestion of central vein $(\leftarrow)$, scattered areas of necrosis $(\mathbf{N})$, inflammatory infiltrate (F), dilated sinusoid (S), karyorrhexis( ${ }^{*}$ ) and karyolysis (+).(H\&E X 400). 


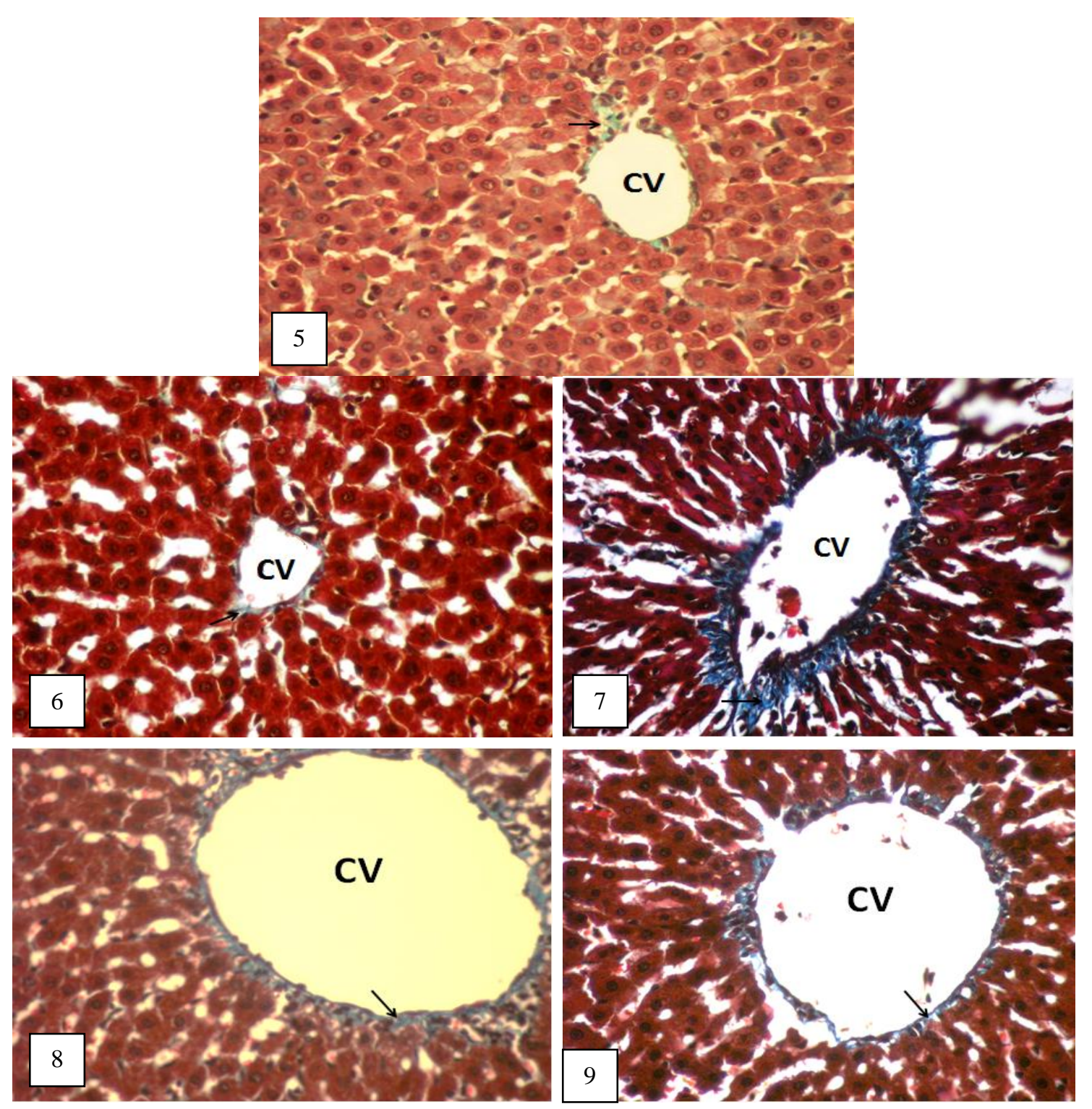

Fig.(5): Paraffin section of normal control rat liver showing thin blue rims of collagen $(\rightarrow)$ around central vein $(\mathrm{CV})$ and sinusoids. (Masson's Trichrome Stain x 400).

Fig.(6): Paraffin section of rat liver after receiving L-arginine for 28 days showing thin blue rims of collagen $(\rightarrow)$ around central vein (CV) and sinusoids. (Masson's Trichrome Stain x 400).

Fig. (7): Paraffin section of rat liver after receiving MTX for 28 days showing strong thickening of collagen fibers $(\rightarrow$ )around congested central vein (CV) and sinusoids. (Masson's Trichrome Stain x 400).

Fig.(8): Paraffin section of rat liver after treatment with L-arginine 2 hrs before MTX for 28 days showing moderate collagen deposition $(\rightarrow$ )around central vein(CV) and sinusoids.(Masson's Trichrome Stain x 400).

Fig.(9): Paraffin section of rat liver after treatment with L-arginine 2 hrs after MTX for 28 days showing moderate collagen deposition $(\rightarrow$ around central vein(CV) and sinusoids.(Masson's Trichrome Stain x 400). 

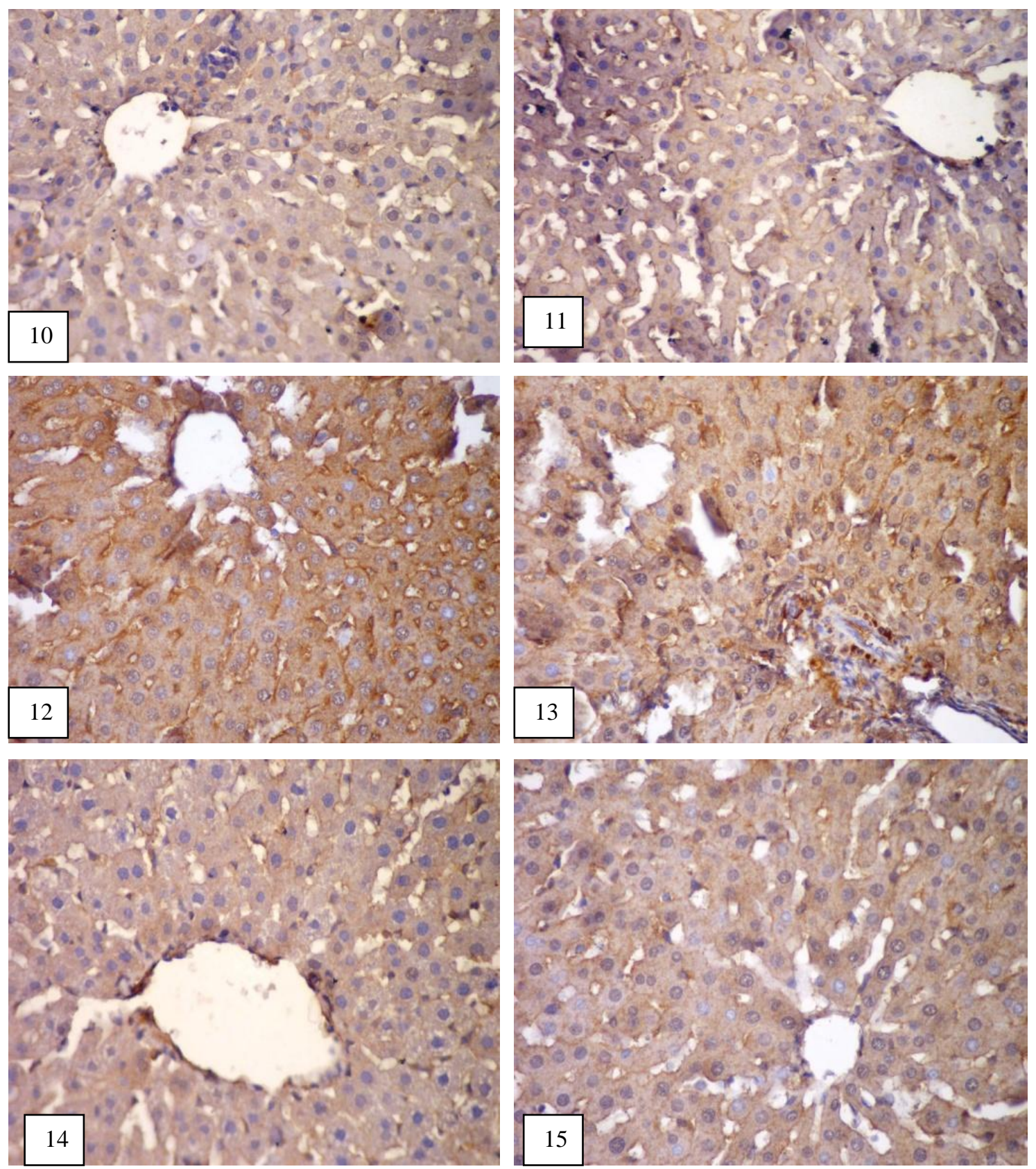

Fig.(10): Paraffin section of normal control rat liver showing mild expression of $\alpha$-SMA (immunohistochemical Stain x 400).

Fig.(11): Paraffin section of rat liver after receiving L-arginine for 28 days showing mild expression of $\alpha$-SMA (immunohistochemical Stain x 400).

Fig. (12): Paraffin section of rat liver after receiving MTX for 28 days showing strong positive staining $\alpha$-SMA in the sinusoids (immunohistochemical Stain x 400).

Fig. (13): Paraffin section of rat liver after receiving MTX for 28 days showing strong homogenous positive staining $\alpha$ SMA around central vein (immunohistochemical Stain $\mathrm{x} 400$ ).

Fig.(14): Paraffin section of rat liver after treatment with L-arginine 2 hrs before MTX for 28 days showing moderate expression of $\alpha$-SMA (immunohistochemical Stain x 400).

Fig.(15): Paraffin section of rat liver after treatment with L-arginine 2 hrs after MTX for 28 days showing reduction of expression of $\alpha$-SMA (immunohistochemical Stain x 400). 
Table (2): Comparison between the different studied groups according to the mean value of percentage area of trichrome positivity.

\begin{tabular}{|c|c|c|c|c|c|}
\hline Groups & Control & L-arginine & Methotrexate & Pre-treated & Post-treated \\
\hline $\begin{array}{c}\text { collagen } \\
\text { (mean value } \% \\
\text { area) }\end{array}$ & $\begin{array}{c}14.91 \\
\pm \\
0.390\end{array}$ & $\begin{array}{c}15.61 \\
\pm \\
0.258 \\
\end{array}$ & $\begin{array}{c}36.39 \\
\pm \\
0.435^{\mathrm{a}, \mathrm{b}}\end{array}$ & $\begin{array}{c}16.59 \\
\pm \\
0.567^{c}\end{array}$ & $\begin{array}{c}18.36 \\
\pm \\
0.400^{\mathrm{a}, \mathrm{b}, \mathrm{c}} \\
\end{array}$ \\
\hline $\mathbf{P}_{1}$ & & & $<0.0001$ & 0.486 & 0.0014 \\
\hline $\mathbf{P}_{2}$ & & & & $<0.0001$ & $<0.0001$ \\
\hline $\mathbf{P}_{3}$ & & & & \multicolumn{2}{|c|}{0.0534} \\
\hline
\end{tabular}

-P : values for Tukey's multiple comparisons test for comparing between control group and each other group. - $\mathrm{P}_{1}$ : values for Tukey's multiple comparisons test for comparing between L-arginine group and each other group. $-\mathrm{P}_{2}$ : values for Tukey's multiple comparisons test for comparing between MTX group and each other group. $-\mathrm{P}_{3}$ : value for Tukey's multiple comparisons test for comparing between pre-treated group \&post-treated group.

- Values are mean \pm SEM.

- a, b, c or d: indicates a significant difference from control, L-arginine, Methotrexate, protection or curative groups, respectively at $\mathrm{p}<0.05$ using one way ANOVA followed by Tukey-Kramer test for multiple comparisons.

Table (3): Comparison between the different studied groups according to the mean value of percentage area of $\alpha$-SMA positivity.

\begin{tabular}{|c|c|c|c|c|c|}
\hline $\begin{array}{c}\text { Groups } \\
\text { Parameters }\end{array}$ & Control & L-arginine & Methotrexate & Pre-treated & $\begin{array}{c}\text { Post- } \\
\text { treated }\end{array}$ \\
\hline $\begin{array}{c}\text { Alpha-SMA } \\
\text { (mean value } \\
\text { \% area) }\end{array}$ & $\begin{array}{c}26.14 \\
\pm \\
1.717\end{array}$ & $\begin{array}{c}29.17 \\
\pm \\
1.099\end{array}$ & $\begin{array}{c}54.38 \\
\pm \\
3.236^{\mathrm{a}, \mathrm{b}}\end{array}$ & $\begin{array}{c}32.02 \\
\pm \\
1.205^{\mathrm{c}}\end{array}$ & $\begin{array}{c}34.88 \\
\pm \\
1.509^{\mathrm{a}, \mathrm{c}}\end{array}$ \\
\hline $\mathbf{P}$ & & 0.795 & $<0.0001$ & 0.230 & 0.030 \\
\hline $\mathbf{P}_{1}$ & & & $<0.0001$ & 0.828 & 0.256 \\
\hline $\mathbf{P}_{2}$ & & & & $<0.0001$ & $<0.0001$ \\
\hline $\mathbf{P}_{3}$ & & & & \multicolumn{2}{|c|}{0.827} \\
\hline
\end{tabular}

-P : values for Tukey's multiple comparisons test for comparing between control group and each other group.

- $\mathrm{P}_{1}$ : values for Tukey's multiple comparisons test for comparing between L-arginine group and each other group.

$-\mathrm{P}_{2}$ : values for Tukey's multiple comparisons test for comparing between MTX group and each other group.

$-\mathrm{P}_{3}$ : value for Tukey's multiple comparisons test for comparing between pre-treated group \&post-treated group.

also in protection group there was no significant increase in the enzyme level compared to normal control group, while curative group showed an increase by $46.8 \%$ compared to normal control (Fig.17). L-arginine did not induce any significant results in total bilirubin serum level compared to normal control group, while Methotrexate induced significant increase in total bilirubin serum level mounted to $152.7 \%$. This increase in total bilirubin serum level was diminished in protective and curative groups to $18.2 \%$ and $30 \%$ respectively comparing to normal control, but the difference between the two groups was not statistically significant ( $\mathrm{P}>0.05)$ (Fig.18). 


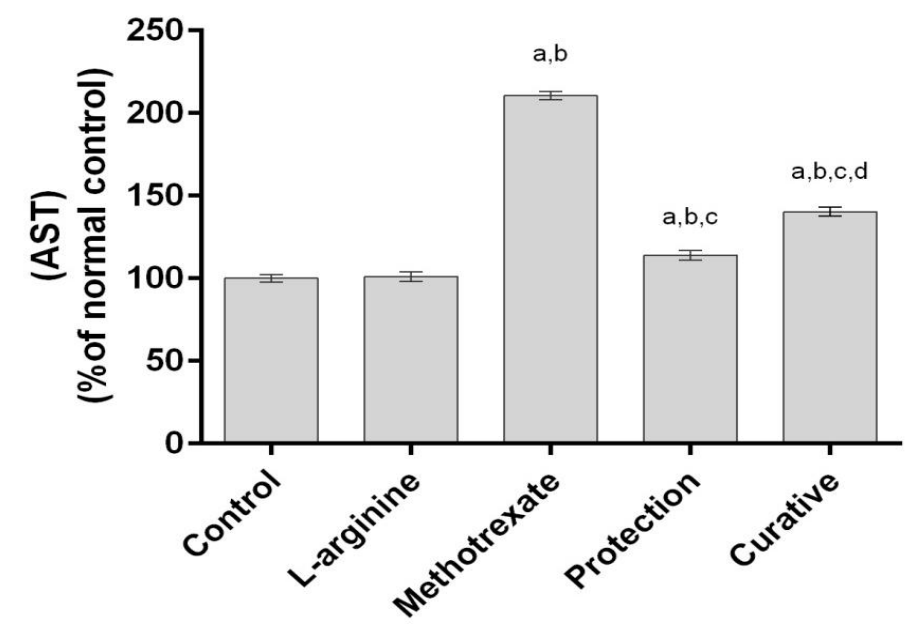

Fig. (16 ):Protective and curative effect of L-arginine on AST serum level in Methotrexate-induced hepatotoxicity in rats

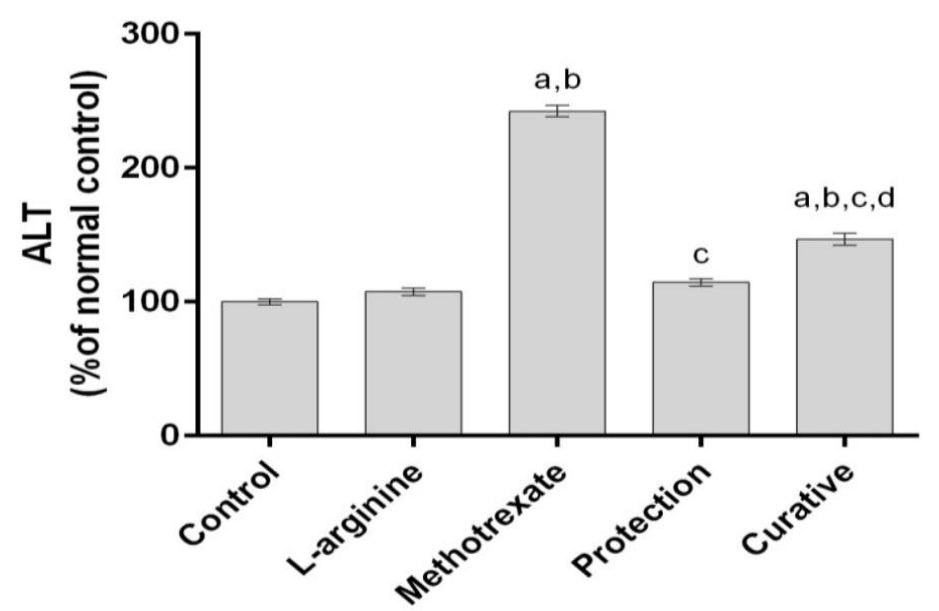

Fig. (17): Protective and curative effect of L-arginine on ALT serum level in Methotrexate-induced hepatotoxicity in rats

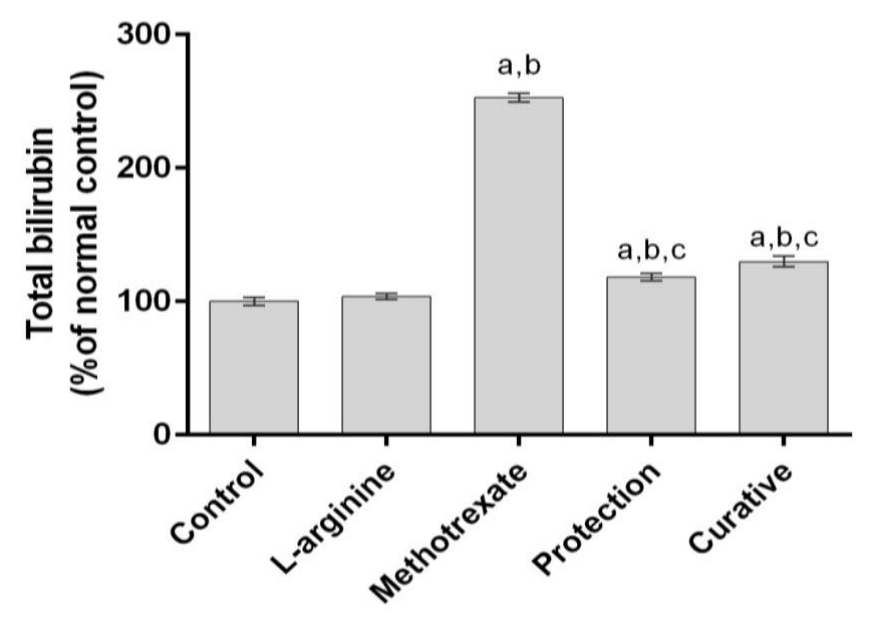

Fig. (18): Protective and curative effect of L-arginine on total bilirubin serum level in Methotrexate-induced hepatotoxicity in rats. 


\section{b. Change in hepatic oxidative stress markers}

Table (3) showed the protective and curative effect of oral administration of $300 \mathrm{mg} / \mathrm{kg}$ L-arginine for 4 weeks on hepatic glutathione, lipid peroxidation and superoxide dismutase activity in MTX-induced hepatotoxicity in rats. Hepatic GSH of MTX- intoxicated rats was markedly decreased by $52.62 \%$ compared to normal control. In Protected group a significant increase of hepatic GSH was observed compared to MTX-intoxicated group. The same was observed in curative group also, as the reduction of GSH level in the two latter groups was $8.35 \%$ and $17.85 \%$ respectively compared to normal control. Group that received L- arginine only showed a significant increase in hepatic GSH by $9.3 \%$ compared to normal control. The levels of liver MDA, as products of lipid peroxidation, were increased after treatment with MTX to levels found to be significantly higher than those in the control animals by $80.55 \%$.On the other hand, pre and post-administration of L-arginine to the MTX-treated rats significantly reduced the MDA levels compared with the MTX group to 23.03\% and $47.36 \%$ respectively compared to normal control. Also, group that received L-arginine only did not show any significant change in lipid peroxidation compared to normal control. A significant increase mounted to $49.1 \%$ compared to normal control was observed in hepatic SOD activity in rats that only received L-arginine .On the other hand, SOD activity was markedly reduced in Methotrexateintoxicated group by $50.16 \%$ compared to normal control. Protection with L-arginine did not only normalize SOD activity, but also induced significant increase amount to $21.1 \%$ compared to normal control. In curative group the activity of SOD was normalized to the normal control.

\section{Discussion}

Hepatotoxicity is a potential adverse effect of a large number of drugs. In the present study, MTX treated rats showed a significant increase in the relative liver weight compared to the control group suggesting hypertrophy of the liver. This increase is in harmony with Moghadam et al., (2015) who used single dose of $20 \mathrm{mg} / \mathrm{kg}$ of MTX IP in rats. Additionally Mukherjee et al., (2013) reported an increase in the relative liver weight by $52 \%$ compared to control group after a single IP injection of MTX.

Histological results revealed different histopathological changes in liver of MTX-treated rats. These results are in agreement of some investigators. The histological abnormalities in patient treated with MTX include nonspecific histological feature such as fatty change, focal liver cell necrosis, portal tract inflammation, nuclear pleiomorphism and fibrosis with collagen accumulation in the peri-sinusoidal space (Laharie et al., 2008, Gilbert et al., 1990). Hadi et al.,(2012) observed focal areas of necrosis in livers of rats exposed to MTX and Dalaklioglu et al.(2013) observed increased numbers of activated Kupffer cells in liver tissues of MTX-administered rats. The present results also showed an apparent increase in the amount of collagen fibers in liver of MTX-treated rats. Similarly, Al-
Motabagani, (2006) reported that MTX caused increase in the amount of collagen fibers particularly around blood vessels in portal tract. Also, the immunohistochemical stained sections of liver treated with MTX showed strong immunoreactive expression of $\alpha$ - SMA. This result is in accordance with Hussein et al. (2015) who found increased expression of $\alpha$ - SMA of liver treated with MTX and they added that liver fibrosis is a consequence of chronic hepatitis and involves the abnormal accumulation of extracellular matrix proteins, particularly collagen.

In the present study, administration of Methotrexate (MTX) caused a significant increase in the serum levels of ALT and AST reflecting impaired liver function. These findings are in agreement with Moghadam et al., (2015) and Mukherjee et al., (2013). Also, El-Naggar et al., 2010 treated rats with IM injected MTX twice weekly for 45 days to study the effect of fucoidan, brown algae extract, against methotrexate hepatic toxicosis and reported a significant increase in AST and ALT serum levels compared to normal control group considering them as biochemical indicators of liver damage.

ALT is a cytosolic enzyme of the hepatocyte and an increase in its activity in serum reflects a leakage in plasma membrane permeability, which in turn, is associated with cell death. ALT is considered to be one of the best indicators of liver necrosis (Gralnek et al., 2000). ALT and AST are the major critical enzymes in the biological processes. They are involved in the breakdown of amino acids into keto acid, which is routed for complete metabolism through the Krebs cycle and electron transport chain (Maiti et al., 2004). Administration of MTX in this study produced a significant increase in total serum bilirubin level. Since the liver is responsible for clearing the blood of bilirubin (Nyblom et al., 2006), so increasing the total serum bilirubin level indicated a reduction in the excretory capability of the liver as a consequence of liver injury.

Oxidative stress represents a disturbance in the equilibrium status of prooxidant/antioxidant reactions in living organisms; it may be a result of an increase in oxidant generation, a decrease in antioxidant production or a failure to repair oxidative damage. Oxidative stress and nitrosative stress are the main cause of the potential damage of free radicals in biological systems. Oxidative stress activates the expression of a wide range of genes that mediate the pathogenic effect of reactive oxygen species (ROS) or are required for the detection and detoxification of the oxidants (Ma,2010). ROS levels are normally controlled by intracellular antioxidant defense mechanisms that include low molecular weight antioxidants and antioxidant enzymes (Gutteridge et al., 1995). In the present work, MTX causes oxidative tissue damage by increasing lipid peroxidation in the liver tissue and decreasing the level of antioxidant enzymes, which cause hepatic necrosis, inflammation, and fibrogenesis. The conversion of MTX to its major extracellular metabolite (7-hydroxymethotrexate) takes place in the liver, where it is oxidized by a soluble enzymatic system (Johovic et al., 2003). 
Table (4): Protective and curative effect of L-arginine on some hepatic oxidative stress markers in Methotrexateinduced hepatotoxicity in rats.

\begin{tabular}{|c|c|c|c|c|c|}
\hline Parameters & Control & L-arginine & Methotrexate & Protected & curative \\
\hline $\begin{array}{c}\text { GSH } \\
\text { (mg/g. tissue) }\end{array}$ & $\begin{array}{c}36.14 \\
\pm \\
0.456\end{array}$ & $\begin{array}{c}39.5 \\
\pm \\
0.282^{\mathrm{a}}\end{array}$ & $\begin{array}{c}17.12 \\
\pm \\
0.295^{\mathrm{a}, \mathrm{b}}\end{array}$ & $\begin{array}{c}33.12 \\
\pm \\
2.81^{\mathrm{a}, \mathrm{b}, \mathrm{c}}\end{array}$ & $\begin{array}{c}29.69 \\
\pm \\
0.337^{\mathrm{a}, \mathrm{b}, \mathrm{c}, \mathrm{d}}\end{array}$ \\
\hline $\begin{array}{c}\text { SOD } \\
\text { (U/mg tissue } \\
\text { protein) }\end{array}$ & $\begin{array}{c}7.38 \\
\pm \\
0.392\end{array}$ & $\begin{array}{c}11.01 \\
\pm \\
0.409^{\mathrm{a}}\end{array}$ & $\begin{array}{c}3.68 \\
\pm \\
0.179^{\mathrm{a}, \mathrm{b}}\end{array}$ & $\begin{array}{c}8.94 \\
\pm \\
0.319^{\mathrm{a}, \mathrm{b}, \mathrm{c}}\end{array}$ & $\begin{array}{c}7.15 \\
\pm \\
0.425^{\mathrm{b}, \mathrm{c}, \mathrm{d}}\end{array}$ \\
\hline $\begin{array}{c}\text { MDA } \\
\text { (nmol/g. tissue) }\end{array}$ & $\begin{array}{c}12.29 \\
\pm \\
0.3596\end{array}$ & $\begin{array}{c}12.05 \\
\pm \\
0.245\end{array}$ & $\begin{array}{c}22.19 \\
\pm \\
0.374^{\mathrm{a}, \mathrm{b}} \\
\end{array}$ & $\begin{array}{c}15.12 \\
\pm \\
0.354^{\mathrm{a}, \mathrm{b}, \mathrm{c}} \\
\end{array}$ & $\begin{array}{c}18.11 \\
\pm \\
0.31^{\mathrm{a}, \mathrm{b}, \mathrm{c}, \mathrm{d}} \\
\end{array}$ \\
\hline
\end{tabular}

- Values are mean \pm SEM of five animals.

- a, b, c or d: indicates a significant difference from control, L-arginine, Methotrexate, protection or curative groups, respectively at $\mathrm{p}<0.05$ using one way ANOVA followed by Tukey-Kramer test for multiple comparisons.

Concerning the effect of L-arginine, the present results showed that L-agrinine minimized the hepatotoxicity of MTX. It decreased the level of ALT, AST and bilirubin ,MDA and increased the antioxidant enzymes.Many reports declared the protective effects of L-arginine. L-arginine is beneficial in the treatment of hepatic injury, hepatic cirrhosis and fatty liver degeneration (Hendler and Saul, 1999, Balch et al., 1997). L-arginine (the precursor for NO) which has many physiological functions, including scavenging of superoxide and altering ROS metabolism (Bailey et al., 2010). Kim et al., (1997) reported that NO is necessary for optimal liver circulation. Andoh et al. (1997) showed that L-Arginine treatment significantly enhanced NO biosynthesis and protected rat kidneys from impaired glomerular filtration rates and development of tubulointerstitial fibrosis after chronic CyA nephrotoxicity. Also, L-arginine co-supplementation to ethylene glycoltreated rats prevents the retention of calcium oxalate crystals by way of protecting the renal cells from oxidative injury ( Pragasam et al.,2005).

There is accumulating evidence showing that L-arginine has a protective role against oxidative stress, and this action is likely mediated via its interaction with $\left(\mathrm{O}_{2}{ }^{-}\right)$ (Leeuwenburgh and Heinecke, 2002, Bailey et al.,2010). Chander and Chopra, (2005) reported that pretreatment of ischemic rats with molsidomine and L-arginine markedly attenuated renal dysfunction, improved the tissue as well as urine NO contents, reduced elevated thiobarbituric acid reactive substances levels and restored the depleted renal antioxidant enzymes. L-arginine administration was found to decrease hepatic lipid peroxidation induced by $\mathrm{CCl}_{4-}$ intoxication, enhances the activities of hepatic antioxidant enzymes (SOD, catalase, GR, GPx and GST) and leads to improvement in liver pathological changes, suggesting that $\mathrm{L}$-arginine is somehow combating $\mathrm{CCl}_{4}$ induced liver hepatotoxicity (Saad, 2012). Adding L-Arginine to the diet of the cyclosporine-administered rats significantly decreased liver cell infiltration. At the same time, rarely observed necrotic areas in the liver of cyclosporine group were not seen in the cyclosporine + L-Arginine group (Kurus et al., 2008). Arginine aids in liver detoxification by neutralizing ammonia, and may benefit in the treatment of liver disorders such as liver injury, hepatic cirrhosis, and fatty liver degeneration (Braverman, 1997).

It is concluded from the present work that L-arginine protects liver from hepatotoxicity of methotrexate and this due to its antioxidant activity.

\section{References}

Al-Motabagani, M., A. (2006).Histological and histochemical studies on the effects of mehotrexate on the liver of adult male albino rat.Int. J. Morphol, 24(3):417422.

Andoh, T.,F., Gardner, M., P., Bennett, W., M.(1997). Protective effects of dietary L-arginine supplementation on chronic cyclosporine nephrotoxicity. Transplantation; 64: 1236-40.

Bailey, S.J., Winyard, P.G., Vanhatalo, A., Blackwell, J.R., DiMenna, F.J., Wilkerson, D.P., Jones, A.M. (2010).Acute l-arginine supplementation reduces the O2 cost of moderate-intensity exercise and enhances highintensity exercise tolerance. J Appl Physiol., 109: 13941403. 
Balch, M.D., James, F. and Balch, C. N. C., Phyllis, methotrexate hepatic toxicosis in albino rats. International A.( 1997). Prescription for Nutritional Healing, Second Journal of Advanced Research., 3(1): 504-514 Edition (Garden City Park, NY: Avery Publishing Group), 35-36. ISBN 0-89529-727-2.

Bancroft, J.,D., Stevens, A.(2002).Theory and practice of histopathological techniques. $4^{\text {th }}$ ed. Chrchillliving stone (pub), New York., pp 116-117.

Braverman, M.,D., E.R. (1997).The Healing Nutrients Within (New Canaan, CT: Keats Publishing, Inc.,

Bredt, D., S., and Snyder, S., H. (1994). Annu. Rev. Biochem.63, 175-195

Brind, A.M.(2011).Drugs that damage the liver. Medicine 2007; 35:26-30

Cetin, A., Kaynar, L., Eser, B., Karada, C., Saraymen, B., Öztürk, A.(2011). Beneficial effects of propolis on methotrexate-induced liver injury in rats. Acta Oncologica Turcica., 44:18-23.

Chander,V., K. Chopra. (2005). Renal protective effect of molsidomine and L-arginine in ischemiareperfusion induced injury in rats, J. Surg. Res., 128 (1): 132- 139.

Chladek, J., Martinkova, J., Sispera, L.(1997). An in vitro study on methotraxate hydoxylation in rat and human liver. Physiol Res., 46: 371-379

Dalaklioglu, S., Genc, GE., Aksoy, NH., Akcit, F., Gumuslu, S.(2013). Resveratrol ameliorates methotrexateinduced hepatotoxicity in rats via inhibition of lipid peroxidation. Hum Exp Toxicol; 32: 662-71.

El-Naggar, A. E., \& Hussein, H. S. (2010). Protective and therapeutic Effects of Fucoidan, brown algae extract, against Diclofenac sodium hepatonephrotoxicity in rat. Egyptain Journal of Comparative Pathology and Clinical Pathology. 23(1):24-28

Gralnek, I., M., Hays, R., D., Kilbourne, A., Rosen, H., R., Keeffe, E., B., Artinian, L. (2000). Development and evaluation of the liver disease quality of life instrument in persons with advanced, chronic liver disease-the LDQOL 1.0. The American Journal of Gastroenterology., 95(12):3552-3565.

Hadi, N., R., Al-Amran, F.,G., Swadi, A.(2012). Metformin ameliorates methotrexate-induced hepatotoxicity. J PharmacolPharmacother. 3: 248-253.

Hibbs, J., r., J., B., Taintor, R., R., Vavrin, Z. and Rachlin, E., M. (1988) Biochem. Biophys. Res.Commun., 157: 87-94

Hussein, S., H., Abdelkadder, Ashraf, M., Fathi, Ahmed, S., Adail. (2015). Protective and therapeutic effects of fucoidan, brown algae extract, against

Jahovic, N., Cevik, H., Sehirli, A., O., Yeğen, B., C., Sener, G., (2003).Melatonin prevents methotrexate-induced hepatorenal oxidative injury in rats. J Pineal Res., 34(4):282-287.

Jendrassik, L., and Gróf, P. (1938). Vereinfachte photometriache methoden sur Bestimmung des blut bilirubins'. Biochemische Zeitschrift., 297: 81- 89.

Kamen, B., A., Nylen, P., A., Camitta, B., M., Bertno, J., R. (1981). Methotrexate accumulation and folate depletion in cell as a possible mechanism of chronic toxicity to the drug. Br J Hematol., 49: 355-360

Kierman, J., A. (2001). Histological and histochemical methods: Theory and practice. $3^{\text {rd }}$ ed. Oxford University press, London. pp 154-5.

Kim, Y., M., Talanian, R.,V., Billiar, T., R. (1997). Nitric Oxide inhibits apoptosis by preventing increases in caspase-3-like activity via two distinct mechanisms. Biol Chem., 272: 31138-48

Kose, E., Sapmaz, H., I., Sarihan, E., Vardi, N., Turkoz, Y., Ekinci, N.(2012).Beneficial effects of montelukast against methotrexate-induced liver toxicity: a biochemical and histological study. Scientific World Journal; 987508.

Kremer, J., M., Galivan, J., Streckfuss, A., Kamen, B.(1986).Methotrexate metabolism analysis in blood and liver of rheumatoid arthritis patients. Arth Rheum., 29: 832-835.

Kurus, M., Esrefoglu, M., Karabulut, A., B., Sogutlu, G., Kaya, M., Otlu, A. (2008). Oral L-arginine protects against cyclosporine-induced hepatotoxicity in rats. Exp Toxicol Pathol, 60:411-419.

Maiti, R., Jana, D., Das, U., K., Ghosh, D. (2004). Antidiabetic effect of aqueous extract of seed of Tamarindusindica in streptozotocin-induced diabetic rats. Journal of Ethnopharmacology, 92(1): 85-91.

Marklund, S., Marklund, G. (1974). Involvement of superoxide anion radical in autoxidation of pyrogallol and a convenient assay for SOD. Eur J Biochem., 47: 469-74.

Moghadam, A. R., Tutunchi, S., Namvaran-AbbasAbad, A., Yazdi, M., Bonyadi, F., Mohajeri, D., and Ghavami, S. (2015). Pre-administration of turmeric prevents methotrexate-induced liver toxicity and oxidative stress. BMC complementary and alternative medicine, 15(1): 246.

Mukherjee, S., Ghosh, S., Choudhury, S., Adhikary, A., Manna, K., Dey, S., \&Chattopadhyay, S. (2013). Pomegranate reverses methotrexate-induced oxidative stress and apoptosis in hepatocytes by modulating Nrf2- 
NF- $\kappa$ B pathways. The Journal of nutritional biochemistry., 24(12), 2040-2050.

Nyblom, H., Björnsson, E., Simrén, M., Aldenborg, F., Almer, S., and Olsson, R. (2006). The AST/ALT ratio as an indicator of cirrhosis in patients with PBC. Liver Int., 26 (7): 840-845.

Okawa, H., Ohishi, N., Yagi, K. (1979). Assay for lipid peroxides in animal tissues by thiobarbituric acid reaction. Anal Biochem., 95 (2): 351- 8.

Pragasam, V., P., Kalaiselvi, K., Sumitra, S., Srinivasan, P., Varalakshmi. (2005).Counteraction of oxalate induced nitrosative stress by supplementation of Larginine, a potent antilithic agent. Clinica Chimica Acta., 354 (1-2): 159-166.

Reitman, S., Frankel, S. (1957). A colorimetric method for the determination of serum level of glutamate oxaloacetic and pyruvate transaminases. Am J Clin Path., 28:56-63.

Richardson, R., J., Murphy, S., D. (1975). Effect of glutathione depletion on tissue deposition of methyl mercury in rats. Toxicol Appl Pharmacol., 31: 505-19.

Roth, E. (1998). The impact of L-arginine-nitric oxide metabolism on ischemia/reperfusion injury. Current Opi- nion in Clinical Nutrition \& Metabolic Care.,1: 97-99
Saad, E., A. (2012). Curative and protective effects of L-arginine on carbon tetrachloride-induced hepatotoxicity in mice. Biochemical and Biophysical Research Communications., 423: 147-151

Scibior, D., and Czeczot, H. (2004). Argininemetabolism and functions in the human organism. Postępy Higieny i Medycyny Doświadczalnej., 58: 321-332.

Skalli, O., Ropraz, P., Trzeciak, A., Benzonana, G., Gillessen, D., Gabbiani, G. (1986). Amonoclonal antibody against $\alpha$-smooth muscle actin: A new probe for smooth muscle differentiation. J Cell Biol., 103:2787-96.

Snedecor, G., W., and Cochran, W., G. (1980). Statistical methods. $7^{\text {th }}$ ed. Lowa State University Press. Ames.

Soliman, M., E. (2009). Evaluation of the possible protective role of folic acid on the liver toxicity induced experimentally by methotrexate in adult male albino rats. Egypt J Histol., 32:118-128.

Wouter, J., Karin, L., Anje, A., Sander, J.H., Martijn, A., Reina, E., Jan, M., Marinus, C. and Wouter, H. (2002). Arginine deficiency affects early B cell maturation and lymphoid organ development in transgenic mice. Journal of Clinical; Investigation., 110: 1539-1548 